\title{
Subprograma Basta e a violência doméstica: ações socioeducativas realizadas no programa patronato do município de Campo Mourão-PR
}

Subprogram Basta and domestic violence: social and educational actions in the patronage program in the city of Campo Mourão-PR

Ingrit Yasmin Oliveira da Silva Batista ${ }^{1}$, Fabiane Freire França²

1 Universidade Estadual de Maringá - UEM, Programa de Pós-Graduação em Educação, Brasil, E-mail: prof.ingrityasmin@gmail.com, ORCID: https://orcid.org/0000-0002-3658-3063

2 Universidade Estadual de Maringá - UEM, Programa de Pós-Graduação em Educação, Brasil, E-mail: prof.fabianefreire@gmail.com, ORCID: https://orcid.org/0000-0001-9781-9773

ART I C LE I N F O

Article history:

Received 2021-06-29

Accepted 2021-08-02

Available online 2021-08-02
Palavras-chave: Subprograma Basta. Violência doméstica. Ações socioeducativas. Educação não escolar.

Keywords: Subprogram Basta. Domestic violence. Social and educational actions. Non-school education.

RESUMO. Este texto visa relatar uma experiência didático-pedagógica de uma prática de Estágio Supervisionado do $4^{\circ}$ ano, do curso de Pedagogia, da Universidade Estadual do Paraná - UNESPAR, na modalidade da educação não escolar. A pesquisa foi desenvolvida com participantes do Programa Patronato no município de Campo Mourão - PR, sendo 8 homens e 1 mulher, que foram atendidos/as pelo Subprograma Basta, com o objetivo de proporcionar reflexões e discussões sobre violência doméstica e familiar. As atividades foram realizadas durante o segundo semestre do ano de 2017. Constatamos que as ações realizadas propiciaram momentos de reflexões e contribuíram para a reinserção social dos/as participantes.

ABSTRACT: Our goal is to describe a didact-pedagogical experience in the scope of a Supervised Practice in the $4^{\text {th }}$ year of the Pedagogy course, in the State University of Paraná - UNESPAR, in the category of non-school education. This research was developed with the participation of the beneficiaries of the Patronage Program in the city of Campo Mourão - PR, 8 males and 1 female, who were attended by the Subprogram Basta, whose goal is to promote reflections and discussions on domestic and family violence. We conclude that the activities carried out in the context of this study provided moments of reflection and contributed to the social reintegration of the participants. 


\section{Introdução}

No decorrer do presente texto apresentamos um relato de experiência do Estágio Supervisionado, na modalidade da educação não escolar, desenvolvido no $4^{\circ}$ ano da Graduação em Pedagogia pela Universidade Estadual do Paraná UNESPAR, vinculado ao Programa Patronato e ao Subprograma Basta do Município de Campo Mourão, Paraná.

Tivemos como objetivo demonstrar a possibilidade de refletir, por meio de ações socioeducativas e diálogos, com os/as assistidos/as do Programa Patronato para que os/as mesmos/as relacionassem suas experiências com as atividades propostas para que não houvesse reincidência de infrações.

Nesse sentido, problematizamos: qual o papel do/a Pedagogo/a na Educação não escolar, especificamente no Patronato? Destacamos que todos/as os/as atendidos/as são pessoas que cometeram infrações sociais, dentre elas a violência doméstica, todavia, não tivemos o acesso às violações dos participantes, pois o nosso objetivo não era de juízo de valor, mas da realização de uma prática interventiva que pudesse sensibilizar os/as participantes sobre o combate a violência doméstica e familiar.

Vale lembrar que, havia nove participantes que realizaram as ações, todavia, mesmo que os delitos cometidos não estivessem relacionados com a violência doméstica, todos/as foram convidados/as para que tivessem a carga horária necessária de atividades realizadas, para que assim, suas penas fossem cumpridas e também, pudessem compreender sobre a temática abordada.

As atividades foram desenvolvidas durante cinco encontros, nos meses de junho, julho e agosto do ano de 2017, com carga horária total de 30 horas. Como público alvo, tivemos oito homens e uma mulher, e propomos dialogar sobre a violência doméstica e familiar por meio de ações socioeducativas.

Para tanto, nosso intuito foi sensibilizá-los/as por meio de ações como a exposição de curta-metragem, leitura de imagens, debates, dinâmicas e questionário com questões referentes as desigualdades de gênero, com a finalidade de promover momentos de diálogos para que reconhecessem diferentes narrativas e histórias sobre mulheres e homens.

\section{Patronato e o Subprograma Basta}

O Subprograma Basta é um projeto que tem o objetivo de zelar pela proteção e dignidade da pessoa humana, além de propiciar a reflexão de temas sociais por meio de ações socioeducativas e de encontros com os/as assistidos do Programa Patronato de Campo Mourão-PR, para que os/as mesmos/as possam relacionar suas experiências e se conscientizem de suas práticas infracionais. A Lei №. 7.210/84 que trata de Execução Penal, evidencia em seus artigos $1^{\circ}$ e $2^{\circ}$ que:

[...] A execução penal tem por objetivo efetivar as disposições de sentença ou decisão criminal e proporcionar condições para a harmônica integração social do condenado e do internado [...] A jurisdição penal 
dos Juízes ou Tribunais da Justiça ordinária, em todo o Território Nacional, será exercida, no processo de execução, na conformidade desta Lei e do Código de Processo Penal (BRASIL, 1984, p. 1).

Sendo assim, a proposta para a realização do Estágio Supervisionado na modalidade da Educação não escolar, no Programa Patronato, se justificou, pois o Subprograma Basta é diretamente atrelado às questões da violência doméstica e familiar. Cabe ressaltar que os homens assistidos pelo programa, em sua maioria, são os agressores que cometem a violência contra as mulheres.

De acordo com a Minuta de Regimento Interno do Patronato de Campo Mourão (2013) a instituição conta com uma equipe multidisciplinar de diferentes áreas, composta por advogados/as, administradores/as, assistentes sociais, pedagogas/os e psicólogos/as recém-formados/as e, estudantes dessas áreas de atuação.

O Patronato é órgão de execução penal em meio aberto e tem por objetivo promover ações de inclusão social dos assistidos através do monitoramento, fiscalização e acompanhamento do cumprimento das Alternativas Penais, cuja conceitualização consiste em toda e qualquer forma de cumprimento de pena ou medida alternativa em meio aberto (PARANÁ, 2013, p. 4).

Entretanto, o papel do Subprograma é de realizar as intervenções necessárias para que reflitam sobre os tipos de ações cometidas e haja uma mudança de conduta. Destacamos o papel do/a Pedagogo/a na educação não escolar, especificamente no Patronato.

Reinserir o indivíduo perante a sociedade, priorizando a educação e a qualificação profissional, oferecendo aos assistidos a reflexão e a conscientização da importância da escolarização. Destaca-se ainda, que a equipe de pedagogia busca a garantia dos direitos dos assistidos como cidadãos, oportunizando a inserção e reinserção na educação formal EJA (Educação de Jovens e Adultos), CEEBJA (Centro Estadual de Educação Básica para Jovens e Adultos) e Instituições de Ensino Técnico e Profissional (FADEL et al, 2014, p. 9).

Salientamos que o/a Pedagogo/a na educação não escolar deve priorizar e buscar soluções alternativas para que os problemas sejam solucionados, tendo em vista contribuir para um processo mais democrático e de transformação social dos/as assistidos/as.

Conforme o governo do Estado do Paraná (2006), o Basta é um dos subprogramas do Patronato, que contempla o desenvolvimento de grupos reflexivos para a intervenção junto aos autores de violência doméstica encaminhados pelo juizado. A lei 11.340, de 7 de agosto de 2006 cria mecanismos para coibir a violência doméstica e familiar contra a mulher, por esses motivos refletimos sobre a referida lei com os/as assistidos/as do programa, atendidos/as junto ao subprograma.

Além do Subprograma Basta, que visa o atendimento de autores de violência doméstica, outros dois programas atendem diferentes demandas, sendo eles: Blitz, voltado aos/as autores/as de delitos de trânsito, e o Saiba, que atende usuários/as de substâncias psicoativas (PATRONATO, 2019). 
Conforme ressalta Oliveira et al., (2020) o Programa Patronato de Campo Mourão, sendo um órgão de execuções penais, com o intuito de reinserir socialmente indivíduos que cometeram delitos na justiça, promovia ações com o propósito de cumprir Alternativas Penais. Contudo, a partir do ano de 2020, essas ações foram descontinuadas, e portanto, houve a extinção do Patronato.

Entretanto, as ações socioeducativas promovidas durante o Estágio Supervisionado, no ano de 2017, foram fundamentais e necessárias para os/as participantes, tendo em vista a garantia do acesso ao direito da socialização e reinserção na sociedade. Além disso, a experiência nesse espaço de atuação nãoescolar propicia uma experiência bastante profícua à formação do Pedagogo/a, o que explicitamos melhor no próximo tópico.

\title{
3. Subprograma Basta e o papel do/a pedagogo/a não escolar
}

A atuação do/a pedagogo/a no Patronato é caracterizada como uma educação em espaço não escolar, mas é pensada e refletida para atender e capacitar jovens e adultos que cometeram algum tipo de delito.

Oliveira et al., (2020) explicam a diferença entre educação não escolar e não formal, conforme a seguir.

\begin{abstract}
ao utilizar o termo "não escolar", remetemo-nos ao espaço no qual as ações foram desenvolvidas e que exigiu intencionalidade nas práticas pedagógicas [...] Por sua vez, o termo "não formal" remete-se à educação não formal, entendida, neste artigo, como uma das formas de educação não escolar, ou seja, de um universo de práticas oriundas das orientações teóricas e metodológicas específicas desse tipo de educação (OLIVEIRA ET AL, 2020, p. 369).
\end{abstract}

No mesmo sentido, a autora Gohn (2007) nos informa sobre o que representa a educação não formal.

As práticas da educação não-formal se desenvolvem geralmente fora dos muros da escola - nas organizações sociais, nos movimentos e programas de formação sobre direitos humanos, cidadania, práticas identitárias e lutas contra a desigualdade e a exclusão social (GOHN, 2007 p. 13).

Portanto, as ações desenvolvidas no Programa caracterizam-se como não formal, ou seja, foram desenvolvidas em um espaço não escolar. Todavia, foram planejadas e executadas com orientação da orientadora do Estágio Supervisionado junto à equipe Multidisciplinar da instituição, onde foi desenvolvido o estágio.

Oliveira (2015) menciona que a educação não formal visa atender as necessidades e demandas que estavam fora do espaço escolar. No Brasil, esse tipo de educação, surgiu com o intuito de possibilitar o direito de todas as pessoas aos processos educativos e demonstrar que o acesso à educação deveria ocorrer de maneira uniforme.

Ainda de acordo com Oliveira (2015), cabe ao/a pedagoga do Patronato, desenvolver atividades voltadas ao apoio e encaminhamento do/a egresso/a para a 
educação formal, conforme o caso. Essas ações são realizadas por meio de parcerias sociais com instituições educacionais, sejam públicas ou privadas. O intuito é oferecer, de maneira gratuita, cursos que são realizados no Patronato ou nas instituições participantes, com a finalidade de refletir sobre os atos cometidos pelos/as assistidos/as.

Quanto à escolarização formal, são realizadas orientações que visam inserir o as pessoas assistidas pelo Patronato em escolas que ofertam Educação de Jovens e Adultos.

Ademais, a presente pesquisa tem como intuito proporcionar reflexões diante do quadro de agressões que mulheres sofrem cotidianamente no Brasil. Para Pimenta (1991),

a presença do pedagogo na escola é útil porque este possui um repertório de conhecimentos (das ciências da educação) que pode ajudar a equipe da escola no cumprimento da sua função. Estes conhecimentos precisam estar articulados no processo ensino/aprendizagem com os objetivos sociopolíticos (PIMENTA, 1991, p.178).

Embora destacamos a presença do/a pedagogo/a no ambiente educacional, elucidamos a necessidade dos conhecimentos voltados à educação não escolar para lidar com os desafios da sociedade contemporânea, dentre eles, a violência doméstica. É nesse sentido que as atividades da prática de estágio foram direcionadas. No Brasil, são altos os índices de violência doméstica e são muitas as mulheres que silenciam e continuam sendo agredidas sem denunciar.

A violência contra a mulher (VCM) consiste em qualquer ato violento baseado no gênero, que resulte, ou tenha probabilidade de resultar, em dano físico, sexual, psicológico ou sofrimento para a mulher, incluindo a ameaça de praticar tais atos, a coerção ou privação arbitrária da liberdade em ambiente público ou privado. A violência sofrida pelas mulheres também pode ser denominada violência doméstica (VD) ou violência de gênero (VG) e consiste em um fenômeno extremamente complexo, que atinge mulheres em todas as partes do mundo e tem suas raízes na inter-relação de fatores biológicos, econômicos, culturais, políticos e sociais (SILVA; OLIVEIRA, 2014, p. 2).

No mesmo sentido, Santos (2017, p.1) salienta que no Brasil, cerca de "503 mulheres brasileiras vítimas a cada hora", esses dados são referentes à violência contra a mulher evidenciam que,

$22 \%$ das brasileiras sofreram ofensa verbal no ano passado, um total de 12 milhões de mulheres. Além disso, 10\% das mulheres sofreram ameaça de violência física, $8 \%$ sofreram ofensa sexual, $4 \%$ receberam ameaça com faca ou arma de fogo. E ainda: $3 \%$ ou 1,4 milhões de mulheres sofreram espancamento ou tentativa de estrangulamento e $1 \%$ levou pelo menos um tiro (SANTOS, 2017, p. 1).

Por esse motivo, justificamos pesquisas como essa, no âmbito da Educação não escolar, bem como o Subprograma Basta, para que as vozes das mulheres sejam visibilizadas. De acordo com a Cartilha Lei Maria da Penha (2013), a lei foi criada tendo em vista que entre os anos de 1998 e 2008, muitas mulheres foram vítimas de 
violência no Brasil, sendo agredidas e mortas, em sua maioria, dentro de suas casas pelos seus companheiros. Nessa perspectiva, a Lei 11.340/2006 - Lei Maria da Penha, é considerada uma conquista para as mulheres brasileiras, pois as protege de qualquer tipo de violência seja doméstica ou familiar. Ainda nesse sentido, de acordo com a Lei,

[...] não é indispensável que o agressor more na casa da agredida para que se caracterize a violência doméstica e familiar contra a mulher. Esta também pode ser cometida por pessoas com quem a mulher mantenha vínculo temporário, esporádico ou eventual (CARTILHA LEI MARIA DA PENHA, 2012, p. 7).

Logo, a relação afetiva entre ambo/as não necessariamente deve ser afetiva para deve ser afetiva para ocorra a agressão. Conforme destaca Bastos (2007) a Lei Maria da Penha foi criada em homenagem a Maria da Penha Maia Fernandes, mulher brasileira que foi vítima de violência doméstica durante o casamento, e que representa força e resistência por justiça. A seguir, destacamos como foram organizados os encontros por meio de ações socioeducativas.

\section{Metodologia da pesquisa: ações educativas desenvolvidas no Patronato de}

\section{Campo Mourão-Pr}

As ações socioeducativas desenvolvidas durante o Estágio Supervisionado, com os/as assistidos/as do Subprograma Basta sucederam da seguinte maneira: os encontros ocorreram conforme cronograma previamente autorizado pela coordenação do Patronato de Campo Mourão, PR.

Realizamos explanações sobre a história de vida de Maria da Penha, que foi uma mulher que sofreu violência doméstica, e devido a sua luta por justiça se originou a lei 11.340/2006, além de explicações referente aos tipos mais comuns acerca da violência.

As imagens levadas como maneira sensibilizadora fomentavam cenas de violência doméstica e expuseram diálogos em que a mulher questionava como ela compraria comida para as crianças, e o homem a insultava com xingamentos (MACHADO, 2004).

Dialogamos sobre um infográfico referente aos dados estatísticos da violência doméstica no Brasil do ano de 2017, produzido pelo Fórum Brasileiro de Segurança Pública, que mostra os altos índices de violência doméstica do ano anterior. Os dados apresentam que $40 \%$ das mulheres brasileiras sofreram assédio dos mais variados tipos, especialmente, entre adolescentes e jovens de 16 a 24 anos e, em sua maioria pretas. Além disso, $29 \%$ das mulheres brasileiras já sofreram algum tipo de violência, tendo em vista que os agressores eram conhecidos das vítimas, todavia, apenas $11 \%$ procurou uma delegacia da mulher. (SANTOS, 2017).

Utilizamos como recurso o curta-metragem "Acorda Raimundo... acorda!" (ALVES, 1990), que conta a história de um casal que difere das normas que são apresentadas na sociedade. A mulher trabalha fora do lar, enquanto o homem cuida das crianças em casa e realiza as atividades domésticas. Com isso, tivemos o intuito de mostrar as transformações de papéis masculinos e femininos, destacando as 
questões de gênero, sexualidade, família, conflitos e preconceitos ainda existentes no século XXI.

Para essa atividade, utilizamos o vídeo como recurso metodológico para discutirmos as temáticas mencionadas acima. Com esse curta-metragem, evidenciamos o quanto é importante problematizar e combater a violência doméstica com o intuito de abolir também os preconceitos existentes.

A mídia, com todas as suas ferramentas, hoje detém o poder de fazer crer e ver, gerando mudanças de atitudes e comportamentos, substituindo valores, modificando e influenciando contextos sociais, grupos, constituindo os arquétipos do imaginário, criando novos sentidos simbólicos como árbitros de valores e verdades (SILVA e SANTOS, 2009, p. 2).

Utilizar filmes como recurso para o estágio não escolar, é uma prática que contribui para desconstruir a visão preconceituosa acerca das mulheres. Nesse sentido, para repensar a representação social de inferioridade da mulher em relação ao homem, e produzir outras perspectivas, acreditamos que se faz necessário que práticas rotineiras, excludentes e preconceituosas deem lugar a outras ações, bem como dialogar sobre a igualdade de gênero em outros espaços, por meio de "planejamento, execução, coordenação, acompanhamento e avaliação de projetos e experiências educativas não-escolares" (BRASIL, 2006, p. 3).

Após o curta-metragem exibido, realizamos uma discussão com os/as assistidos/as por meio de perguntas sobre o vídeo: qual é o papel da mulher na sociedade atual? Como seria se as mulheres fossem predominantemente responsáveis pelo espaço público e os homens pelo espaço privado?

A partir das respostas dos/as participantes, mostramos imagens que elucidam as transformações e os avanços que as mulheres tiveram do século XX ao XXI, como: atividades voltadas ao ambiente doméstico, cuidado dos filhos e marido, o direito ao voto, trabalhar fora do lar e a luta pela igualdade de gênero.

Com essas atividades, cumprimos o papel do estágio supervisionado, mediante experiência como pedagogas em mediar todo o processo educativo, "agindo em todos os espaços para a garantia de efetivação de um projeto de escola que cumpra com sua função política, pedagógica e social" (TAQUES ET AL, 2010, p. 27). Em vista disso, na sequência do texto estão elencadas as respostas dos/as assistidos em relação às perguntas realizadas no último encontro das ações desenvolvidas.

\section{Resultados e discussões}

Após os diálogos e exibição das ações, solicitamos que os/as participantes respondessem as questões sobre a temática sem identificarem seus nomes, visando preservar suas identidades. Para a realização das análises desta pesquisa, nos ancoramos nos Estudos de Gênero, em estudos como de autores/as como: França (2014), Fonseca et al. (2009), Saffioti (2004), Sarti (2004) e Rabello e Júnior (2007). As questões realizadas aos/as participantes no questionário foram: 1) O que gera situações de violência doméstica e familiar?; 2) Por que esse assunto é tão relevante e tem que ser combatido? As respostas coletadas por meio das respostas escritas por eles/as foram dialogadas ao final do encontro. Foram realizadas as leituras das respostas, sem identifica-los/as. 
Acerca da questão sobre o que gera violência doméstica e familiar, Alice 1 argumenta que a própria cultura gera a violência, tanto física quanto psicológica. "Álcool e drogas também aumentam esse índice. Pela lei brasileira é quase um incentivo à essa prática onde um crime de violência doméstica é financiável (Sic Trecho extraído do questionário)".

Assim como Alice, entendemos que esses fatores contribuem para o aumento da violência doméstica e familiar. Fonseca et al. (2009) suscita que os estudos da literatura apontam que há diferentes maneiras de violência, todavia, elas aumentam quando os homens, em sua maioria, estão sob efeito do álcool. Para responder a mesma questão, o participante Bernardo relatou que:

Dependendo da situação, é o machismo do homem, mas em algumas casas não é só a mulher que sofre o abuso, o homem também, isso devido a má convivência entre o casal, pois um quer ser melhor que o outro (Sic Trecho extraído do questionário, grifo nosso).

Saffioti $(2004$, p. 64) ressalta que "a violência de gênero ocorre normalmente no sentido homem contra a mulher, mas pode ser perpetrada também por um homem contra outro homem ou por uma mulher contra outra mulher", todavia, casos "em que tanto homens como mulheres aparecem como agressores" visibiliza os problemas relacionados as questões de gênero e, portanto, faz-se necessários atendimentos voltados a essas questões com a vítima e agressor por se tratar de violência familiar (SARTI, 2004, p. 43).

Em relação a questão sobre o porquê do tema ser relevante, o participante Carlos relatou que:

É um assunto cada vez mais polêmico, pois na maioria das vezes a violência doméstica é cometida contra a mulher, e a mulher durante a história lutou para conquistar seus direitos, e devem ser criadas leis mais rígidas quanto a isso [...] e medidas socioeducativas (Sic Trecho extraído do questionário).

Rabello e Júnior (2007) destacam que a violência de gênero deixa consequências físicas e também mentais nas mulheres que as sofrem. No mesmo sentido, França (2014, p. 30) evidencia que é necessário

produzir novos movimentos e teorizações que provoquem mudanças significativas no campo social e, neste sentido, compreender que o movimento histórico é de extrema relevância para trazer à tona ainda mais reivindicações, mudanças e outras representações sociais.

Com isso, fomentamos que no Brasil, são muitas as mulheres que silenciam e continuam sendo agredidas sem denunciar, o que justifica que a pesquisa possibilitou a abertura ao diálogo para que os/as assistidos/as refletissem acerca dos atos cometidos e possivelmente possam ter uma nova conduta.

- Utilizamos as letras sequenciais do alfabeto para preservar a identidade dos/as participantes da pesquisa. Escolhemos nomes fictícios para preservação da identidade dos/as participantes da pesquisa. 


\section{Considerações finais}

Com as experiências obtidas durante o estágio na modalidade não escolar, cabe ressaltar que por muito tempo, as mulheres foram vistas e tratadas como inferiores aos homens e, ainda há muito preconceito da sociedade em relação ao gênero feminino, por isso, a necessidade de problematizar essas questões em todos os ambientes que estão disponíveis e aceitam a possibilidade de diálogo.

Dessa maneira, destacamos a necessidade de trabalhar questões acerca da violência doméstica nos mais diversos espaços, sobretudo, no ambiente não escolar para que os/as participantes percebam e reconheçam as histórias e lutas das mulheres com a intenção de desmistificar os preconceitos que se perpetuam em relação a mulher como o "sexo frágil".

Portanto, o papel do/a pedagogo/a frente às situações de violência, necessita ser de denúncia e não de silenciamento. Ademais, a presente pesquisa tem como intuito proporcionar reflexões diante do quadro de agressões que mulheres sofrem cotidianamente no Brasil.

\section{Referências}

ACORDA Raimundo. Direção: Alfredo Alves. Ibase, 1990. DVD.

BASTOS, Marcelo Lessa. Violência doméstica e familiar contra a mulher Lei no 11.340/06. Revista da EMERJ, v. 1, p. 37, 2007. Disponível em: <https://www.emerj.tjij.jus.br/revistaemerj_online/edicoes/revista37/Revista37_134.p df>. Acesso em: 25 mai. 2021.

BRASIL. CONSELHO NACIONAL DE EDUCAÇÃO. CONSELHO PLENO. Resolução CNE/CP n.. 1, de 15 maio de 2006. Institui Diretrizes Curriculares Nacionais para o Curso de Graduação em Pedagogia, licenciatura. Disponível em: <http://portal.mec.gov.br/cne/arquivos/pdf/rcp01_06.pdf>. Acesso em: 05 jun. 2021.

BRASIL. Presidência da República. Casa

Civil. Subchefia para Assuntos Jurídicos. Lei ํo 11.340 de 7 de agosto de 2006. Brasilia, 8 ago. 2006.

BRASIL. Lei n. 7.210, de 11 de julho de 1984. Institui a Lei de Execução Penal. Disponível em: <http://www.planalto.gov.br/ccivil_03/leis/L7210.htm>. Acesso em: 09 jun 2021.

CARTILHA. Lei Maria da Penha. Lei 11.340/06. Toda mulher tem direito a uma vida livre de violência. Convenção Interamericana para Prevenir, Punir e Erradicar a Violência contra a Mulher, Belém do Pará, 1994. Poder Judiciário do Rio de Janeiro, 2013. Disponível em: <http://www.tjrj.jus.br/documents/10136/3480102/cartilhamaria-penha.pdf>. Acesso em: 04 jun. 2021.

FADEL, Tesserol Joice; BECHER, Caroline; ASSIS, Jeniffer Marcondes de; PEREIRA, Karoline; CONRADO, Daniela Lopes Simão Rodrigues. Programa de execução das alternativas penais do Município de Guarapuava-PR. Anais do IV Seminário Nacional Sociologia \& Política, Curitiba: PR, 2014. Disponível em:<http://docplayer.com.br/15056063-Anais-do-v-seminario-nacional-sociologiapolitica.html> Acesso em: 05 jun. 2021.

FONSECA, Arilton Martins; GALDUROZ, José Carlos Fernandes; TONDOWSKI, Cláudia Silveira; NOTO, Ana Regina. Padrões de violência domiciliar associada ao uso de álcool no Brasil. Rev. Saúde Pública [online]. vol.43, n.5, 2009. p.743-749. FRANÇA, Fabiane Freire. Representações sociais de gênero na escola: diálogo com educadoras. 2014. 186 f. Tese (Doutorado em Educação) - Universidade 
Estadual de Maringá, Maringá, 2014.

GOHN, Maria da Glória. (org). Movimentos Sociais no Início do Século XXI:

Antigos e Novos Atores Sociais. 3. Ed. Petrópolis, RJ: Vozes, 2007.

GOMES, Orlando. Direito de família. Rio de Janeiro: Forense, 1981.

MACHADO, José Luís de Almeida. A situação das mulheres no século XIX. Planeta

Educação, $2004 . \quad$ Disponível em: $<\mathrm{http}: / /$ www.planetaeducacao.com.br/portal/artigo.asp?artigo=203>. Acesso em: mai. 2021.

NAPOLITANO, Marcos. Como usar o cinema na sala de aula. São Paulo: Contexto, 2009.

OLIVEIRA, Daniela Simitan Claro. O pedagogo no processo de reinserção social: patronato penitenciário de Iondrina. Universidade Estadual de Londrina, Londrina, 2015.

OLIVEIRA, Wanessa Gorri de; FRANÇA, Fabiane Freire; GOMES, Érica Fernanda Kalinovski; FERNANDES, Chayenne Malu Camargo. Subprograma "basta" no programa patronato de Campo Mourão: contribuições da pedagogia no combate à violência doméstica e familiar. Revista Humanidades e Inovação. v. 7, n. 7.7, p. 368-380, 2020.

PARANÁ. Municipalização da execução das alternativas penais. Curitiba: Secretária de Estado da Justiça, Cidadania e Direitos Humanos do Paraná, 2013. Disponível

em:<https://www.justica.pr.gov.br/arquivos/File/Patronato/cartilha_patronato_SEJU_ 29.pdf>. Acesso em: 25 mai. 2021.

PATRONATO será extinto a partir de 2020. Najuá, 22 dez. 2019. Disponível em: <https://hojecentrosul.com.br/?id=5806>. Acesso em: 15 mai. 2021.

PATRONATO MUNICIPAL DE CAMPO MOURÃO. Minuta de Regimento Interno. Campo Mourão: 2013 (mimeo).

PIMENTA, Selma Garrido. O pedagogo na escola pública. Loyola: São Paulo, 1991. RABELLO, Patrícia Moreira; JÚNIOR, Arnaldo de França Caldas. Violência contra a mulher, coesão familiar e drogas. Rev. Saúde Pública [online], São Paulo, v. 41, n. 6, p. 970-978, 2007. DOI: https://doi.org/10.1590/S0034-89102007000600012. Disponível

em: $<$ https://www.scielo.br/j/rsp/a/QdVxHbxQwLGCXmGtDTzvvFb/?lang=p $>$. Acesso em: 25 mai. 2021.

SAFFIOTI, Heleieth lara Bongiovani. Gênero, patriarcado, violência. São Paulo: Editora Fundação Perseu Abramo, 2004.

SARTI, Cynthia Andersen. O feminismo brasileiro desde os anos 1970: revisitando uma trajetória. Estudos Feministas, Florianópolis, v. 12, n. 2, p. 264, maio/ago. 2004. SANTOS, Bárbara Ferreira. Os números da violência contra mulheres no Brasil. São Paulo, 8 mar. 2017. Disponível em: <https://exame.com/brasil/os-numeros-daviolencia-contra-mulheres-no-brasil/>. Acesso em: 15 mai. 2021.

SILVA, Ellen Fernanda Gomes da; SANTOS, Suely Emília de Barros. O impacto da mídia sobre a produção da subjetividade. In: Associação Brasileira de Psicologia Social, 2009. Disponível em: <http://www.abrapso.org.br/siteprincipal/images/Anais_XVENABRAPSO/447.\%200\% 20impacto\%20e\%20a\%20influ\%CAncia\%20da\%20m\%CDdia.pdf>. Acesso em: 19 jun. 2021.

SILVA, Lídia Ester Lopes da; OLIVEIRA, Maria Liz Cunha de. Violência contra a mulher: revisão sistemática da produção científica nacional no período de 2009 a 2013. Escola Superior de Ciências da Saúde. Brasília: DF, 2014. Disponível em: 
$<$ http://www.scielo.br/pdf/csc/v20n11/1413-8123-csc-20-11-3523.pdf>. Acesso em: 15 mai. 2021.

SILVA, Marlise Vinagre. Violência contra a mulher: quem mete a colher? São Paulo: Cortez, 1992.

TAQUES, Mariana Fonseca; CARVALHO, Paulla Helena Silva de; DUARTE, Ana Carolina Soares; FANK, Elisane. O papel do pedagogo na gestão: possibilidades de mediação do Currículo. In: PARANÁ, Secretaria de Estado da Educação: Superintendência da Educação. Organização do trabalho pedagógico. Curitiba: SEED, 2010. 